\title{
Whole Body Vibration Exposure among the Tractor Operator during Soil Tillage Operation: An Evaluation using ISO 2631-5 Standard
}

\author{
Amandeep Singh $\left(D,{ }^{1}\right.$ Siby Samuel, ${ }^{1}$ Harwinder Singh, ${ }^{2}$ Jagmeet Singh, ${ }^{2}$ Chander Prakash, ${ }^{3}$ \\ and Yash Kumar Dhabi ${ }^{4}$ \\ ${ }^{1}$ Department of System Design Engineering, University of Waterloo, Waterloo, ON N2L 3G1, Canada \\ ${ }^{2}$ Department of Mechanical Engineering, Guru Nanak Dev Engineering College Ludhiana, Punjab 141006, India \\ ${ }^{3}$ Department of Industrial and Production Engineering, Dr. BR Ambedkar National Institute of Technology Jalandhar, \\ Punjab 144011, India \\ ${ }^{4}$ Trench Technology Center, Louisiana Tech University, Ruston, LA 71272, USA
}

Correspondence should be addressed to Amandeep Singh; ip.nitj@gmail.com

Received 6 October 2021; Revised 24 December 2021; Accepted 29 December 2021; Published 29 January 2022

Academic Editor: Selçuk Erkaya

Copyright (C) 2022 Amandeep Singh et al. This is an open access article distributed under the Creative Commons Attribution License, which permits unrestricted use, distribution, and reproduction in any medium, provided the original work is properly cited.

\begin{abstract}
This study is aimed at investigating the effect of various tractor ride conditions on the lumbar spine during rotavator operation. The lumbar spinal response was assessed by determining static compressive dose, i.e., $\mathrm{S}_{\mathrm{ed}}$ (8). Raw acceleration data were measured on the seat pan and seat backrest to varying tractor velocity, tillage depth, and pulling force. The field experiments have been designed using Taguchi's $\mathrm{L}_{9}$ orthogonal array and the entire data analyzed in signal-to-noise ratios terms. The mean acceleration responses were dominant along the vertical axis and exposure levels were found beyond the exposure action value, i.e., $0.5 \mathrm{~m} / \mathrm{s}^{2}$ as per Directive $2002 /$ 44/EU. Mean $\mathrm{S}_{\text {ed }}$ (8) exceeded the limits of ISO 2631-5 indicating the probability of adverse health effects. Tractor velocity and pulling force have a significant impact on $\mathrm{S}_{\text {ed }}(8)$ with a $64.43 \%$ and $27.73 \%$ percentage contribution. The FFT dominant peaks have been found in the 0.8 to $3.7 \mathrm{~Hz}$ frequency range. Moreover, the exact frequency of the peaks is found to be dependent on the experimental circumstances. The depicted dominant frequencies found in the range of low frequencies could lead to musculoskeletal disorders since they coincide with the natural frequencies of various parts of the body, especially in the lumbar region.
\end{abstract}

\section{Introduction}

Vibration occurs in every vehicle which mainly arises due to the tire-terrain interactions. The magnitude of vibration largely depends on the various vehicle ride conditions along with the terrain conditions [1]. The technological developments overcame the vibration exposure among on-road vehicle drivers/passengers up to a considerable extent whereas the designers and manufacturers are devoting substantial efforts to limit vibration exposure among offroad vehicles such as tractors. Tractors are being used at both on-road and off-road terrain conditions due to their versatility [2]. As of now, the growth of the agricultural sector largely depends on the use of tractors and its mounted machinery. Nowadays, the increase in population has raised the demand for crop productivity and this makes the farmers use mechanized machinery to speed up the crop sowing and harvesting time [3]. The window period (i.e., time between harvesting and sowing of next crop) between crops is required to be as shorter as possible to save field processing time [4]. This includes using advanced machinery to prepare the soil bed for future crop sowing later on during ground tillage operations. Each farm travels through different periods of primary and secondary soil tillage to manipulate the soil to get optimum sowing conditions. There are many tillage implements available such as disc harrow, cultivator, mouldboard plough, shovels, and leveller. Nowadays, the use of rotavators has become popular among farmers due to 
their multipurpose operational quality. Rotavator has been capable of performing both the tillage operation as carried out using harrow and cultivator, thereby used a replacement of these tillers during field preparation. Moreover, this implement has been found very time-saving in cutting the stubbles and clods of hard soil formed after the harvesting of paddy crops. Rotavator is a tractor-mounted implement affixed using a three-point linkage system (TPL). It comprises various types of cutting blade shapes (i.e., L, J, and C-shape) mounted on flanges, as shown in the figure. The connecting shaft tends to produce rotary motion in the blades to manipulate the soil and cutting of the hard clods.

Unlike other vehicles, tractors and its mounted accessories transmit vibratory motion while operated at various ride conditions over uneven terrain [5]. The vibration enters into the driver's body through various contact points between the driver and the vehicle such as the steering wheel, seat, levers, paddles, and floor mainly. The tractor emits vibrations beyond the exposure action value, i.e., $0.5 \mathrm{~m} / \mathrm{s}^{2}$ as recommended by Directive 2002/44/EC [6]. Long-term exposure to such vibrations may lead to health risks among the drivers $[7,8]$. The low vibration frequencies, generally between 1 and $10 \mathrm{~Hz}$, have substantial adverse effect on health [9]. Moreover, the tractor drivers are usually exposed to such low vibrating frequencies at high amplitudes [10]. Kumar et al. [11] inferred that the tractor ride turns out to be uncomfortable mostly due to the dominant frequencies coinciding with the natural frequencies of different human body parts, mainly ranging between 1 and $7 \mathrm{~Hz}$. These critical frequencies can play a leading role in causing musculoskeletal risks especially in the lumbar spine region [3]. Occupational drivers were found at major risk of future low back issues [12]. These disorders were found predominantly among tractor drivers due to the high amplitude of low-frequency vibration exposure [13].

The past research studies have been found limited to investigate the vibration exposure considering tractors without any attached implement [14-16]. These studies mainly examined the impact of vibration concerning different aspects: seat cushion material, tractor speed, gears, tire inflation pressure, suspension system, etc. The majority of the studies were carried out in the laboratory-controlled condition using simulators to study the effect of various parameters such as vibration magnitude [17], sitting posture [18], and backrest inclination [10]. The literature reveals that the past studies had mainly investigated the vibration exposure considering disc harrow [19] and mouldboard plough [20] as tractor attached implements. However, Singh et al. [4] studied the impact of vibration exposure during rotavator operation but was limited to the assessment of overall vibration total value (OVTV) response. So, the present study attempted to investigate the impact of various tractor ride conditions (i.e., tractor velocity, tillage depth, and pulling force) on the driver's lumbar spine during rotavator operation. The lumbar spine response has been assessed in terms of daily equivalent static compression dose $\left(\mathrm{S}_{\mathrm{ed}}(8)\right)$ as per ISO 2631-5 [21]. It has been hypothesized that riding conditions, i.e., tractor velocity, tillage depth, and pulling force, will have a significant impact on $S_{\text {ed }}(8)$.

\section{Materials and Methods}

2.1. Tractor Driver. The present study recruited a 26-yearold single male tractor driver with a stature of $1.52 \mathrm{~m}$, weight of $74 \mathrm{~kg}$, and BMI, i.e., body mass index of $32.02 \mathrm{~kg} / \mathrm{m}^{2}$. The recruited driver belongs to a farming family background and he had approximately 6 years of tractor driving practices. The intention of experimentation was made clear to the driver according to the purpose of the study. The driver had reported no sensitiveness or health issue towards vibration exposure. The driver signed a consent form before he participated in the study experimentation. The study has been carried out by the Declaration of Helsinki, and the protocol was approved by the Ethics Committee of Guru Nanak Dev Engineering College, Ludhiana (letter no. GNDEC/ME/113).

2.2. Test Terrain and Machinery. This study was carried out at Punjab Agricultural University, Ludhiana (India). The university authorities had provided a formal permission (letter no. FM\&PE/896) to use experimentation facilities such as terrain, tractor, rotavator, and other necessary items. A post-harvested terrain with a dimension of $162 \times 85 \mathrm{~m}$ has been used for the present study. Soil samples were collected from different field locations to test the soil texture, moisture, and compactness. The soil texture was found to be sandy clay loam with $69 \%$ sand, $23.6 \%$ clay, and $7.4 \%$ silt. Soil moisture was tested and ranged between $52.9 \%$ and $58.5 \%$. Soil compactness was tested at three varying depth levels, i.e., $0-0.05 \mathrm{~m}, 0.05-0.10 \mathrm{~m}$, and $0.10-0.15 \mathrm{~m}$, and found to be $14 \mathrm{kPa}, 20 \mathrm{kPa}$, and $28 \mathrm{kPa}$, respectively. The study used the 2016 model 55 HP 2-wheel drive tractor " $T$ " equipped with an original company-fitted seat. The existing tires were replaced with newer ones to avoid the effect of wear and tear, whereas the inflation pressure has been set according to tractor catalogue reference, i.e., $210 \mathrm{kPa}$. A $450 \mathrm{~kg}$ and 7 feet rotavator equipped with C-shaped blades having cutting width of $2.137 \mathrm{~m}$ and cutting depth of $0.15 \mathrm{~m}$ was mounted to the tractor during the experimentation. To control tillage depth and pulling force, the tractor was outfitted with two levers with company standard designated points (draught lever: 2, 4, 6, 8, and 10, and position lever: 1 , $3,5,7$, and 9). The average tractor velocity was calculated using a typical technique based on the distance travelled in a certain gear, i.e., first low gear with respective time duration. Tillage depth was measured using a scale to determine lever settings of 5,7 , and 9 . The pulling force was measured with the aid of a dynamometer.

2.3. Orthogonal Array. This study used Taguchi's $\mathrm{L}_{9}$ orthogonal array to formulate a systematic set of experiment trials. Taguchi's tool requires a desired number of input (or ride) parameters with specific levels to design the experiments. Therefore, a pilot survey was carried out to obtain the possible influencing parameters in this particular soil tillage operation. This survey was conducted in a farm fair (i.e., Kisan Mela) organized by Punjab Agricultural University Ludhiana (India). It included direct interviews and 
discussion with a random sample of thirty-five farmers/ tractor drivers, and some preliminary trials were performed with an affixed tractor-rotavator system in the actual field. This exercise provided various parameters out of which three were chosen with specific levels: tractor velocity $(0.6,0.7$, and $0.8 \mathrm{~m} / \mathrm{s})$, tillage depth $(0.10,0.12$, and $0.14 \mathrm{~m})$, and pulling force $(2,4$, and $6 \mathrm{kN})$. Using these parameters and corresponding levels of ride parameters, the orthogonal array provided nine sets of experiments. Each experiment was replicated three times to get an average output response. The output was determined in terms of equivalent static compression dose $\left(S_{\text {ed }}(8)\right) . S_{\text {ed }}(8)$ was determined using the standard procedure recommended by ISO 2631-5 [21], as shown in Figure 1.

The outcome responses were analyzed in signal-to-noise $(\mathrm{S} / \mathrm{N})$ ratios using the minimization function as per Taguchi's standard procedure [22].

2.4. Response Measurement Locations and Instruments. In the present study, the raw acceleration response was measured at two locations: (1) at the seat pan under the ischial tuberosities and (2) at the seat backrest along the three translation axes, i.e., fore and aft $(x)$, lateral $(y)$, and vertical $(z)$ axis. To compute $S_{\text {ed }}(8)$, it was required to get simultaneous measurements along the translational axes at both the locations as recommended by ISO 2631-5 [21]. Therefore, two SV 38 seat pad triaxial sensors were mounted at the seat pan and the seat backrest location with a wired connection through SV 106 six-channel human vibration monitor, as shown in Figure 2. The raw acceleration data were measured for 60 seconds at a sampling rate of $6 \mathrm{kHz}$. Due to limited field availability, it was hard to extend experiment trial for more than 60 seconds. Whereas the SV 106 instrument has maximum capacity to provide 6000 raw data samples per second. A band limit (low pass) weighting filter has been used as per ISO 2631-1 [23] under section A2, page 19.

2.5. Software. The experimental design was formulated using Minitab (version 16.0) to obtain $\mathrm{S} / \mathrm{N}$ ratio response and statistical analysis for $S_{\text {ed }}$ (8). Raw acceleration responses at both locations were recorded and transferred into DEWEsoft DAQ software to obtain root mean square (r.m.s.) magnitude. In addition, raw acceleration files were converted into.txt and analyzed in MATLAB (version 2021) software to get time-acceleration and Fast Fourier Transform (FFT) response along the three translation axes, respectively.

\section{Results and Discussion}

3.1. Raw Acceleration Analysis. The raw acceleration amplitude was analyzed with respect to time duration at both the measuring locations. Experiments were carried out based on the orthogonal array and then the mean amplitude responses of the nine trials have been computed at both seat pan and seat backrest location. The orientation of seat pad accelerometers at the seat and at the backrest can be visualized in Figure 2. The mean outcome response can be

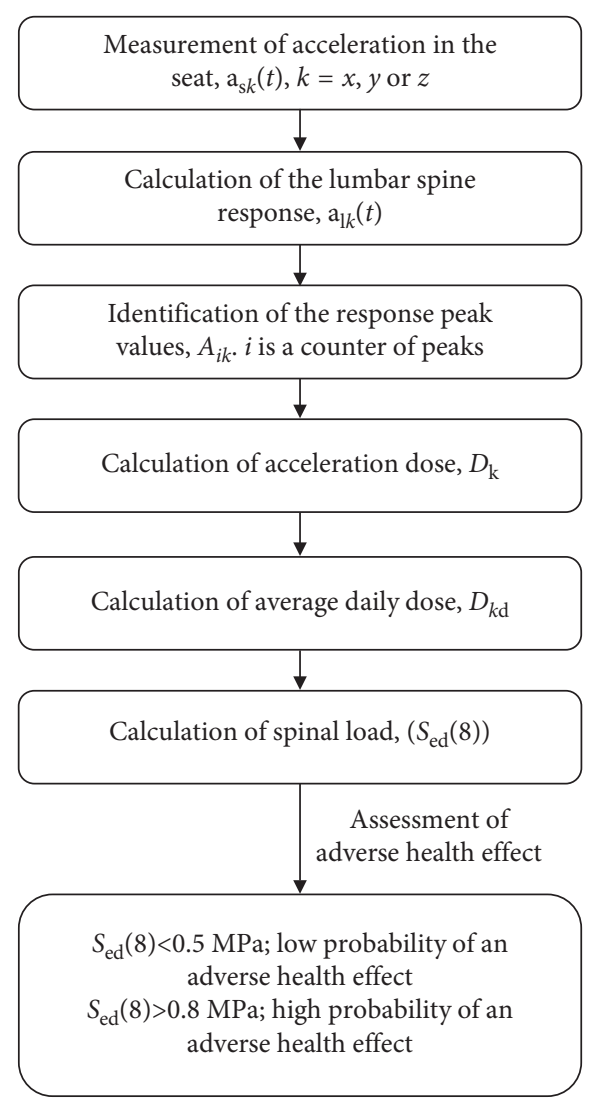

FIGURE 1: Evaluation of spinal load response as per ISO 2631-5 [21].

visualized along the $x, y$, and $z$ axes, as shown in Figures 3(a) and $3(\mathrm{~b})$. The vibration amplitude was found dominant along the $z$-axis at both seat pan and seat backrest locations. However, high vibration amplitudes were seen at some places along the $x$ and $y$ axes at both locations.

In addition, the majority of amplitude signals were exceeding the exposure action value (EAV) limit, i.e., $0.5 \mathrm{~m} /$ $\mathrm{s}^{2}$ as recommended in the Directive2002/44/EU [6]. The long-term exposure to such high amplitude vibration may affect the work capacity as well performance [24].

3.2. Signal-to-Noise Ratio Response. Taguchi's $\mathrm{L}_{9}$ orthogonal array provided nine sets of experimental combinations and each set replicated three times $\left(R_{1}, R_{2}\right.$, and $\left.R_{3}\right)$ to obtain average $S_{\text {ed }}(8)$, as shown in Table 1.

It can be seen that $S_{\text {ed }}(8)$ response ranged between 0.38 and $0.76 \mathrm{MPa}$ among the experimental trials. Whereas, the mean $\mathrm{S}_{\text {ed }}(8)$ response, i.e., $0.55 \mathrm{MPa}$, indicated the significant probability of occurrence of health impact as per ISO 2631-5 [21]. On the contrary, the $\mathrm{S} / \mathrm{N}$ ratio response was found between 2.38 and 8.49 among the experiments. The experiment with the highest $S_{\text {ed }}(8)$ indicated the lowest $S / N$ ratio response and vice versa, as shown in Table 1. In addition, the effect of each ride parameter and their interactions on $S_{\text {ed }}(8)$ has been presented in Figure 4 . The mean $S_{\text {ed }}$ (8) response was found to decrease with the increase in tractor velocity and pulling force as per $\mathrm{S} / \mathrm{N}$ ratios, i.e., $\mathrm{S}_{\text {ed }}$ (8) increases with the increase in velocity levels from 0.6 to 


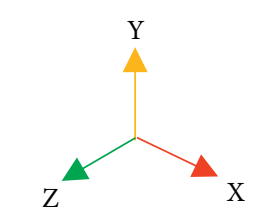

Accelerometer orientation at backrest

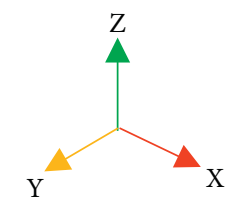

Accelerometer orientation at seat

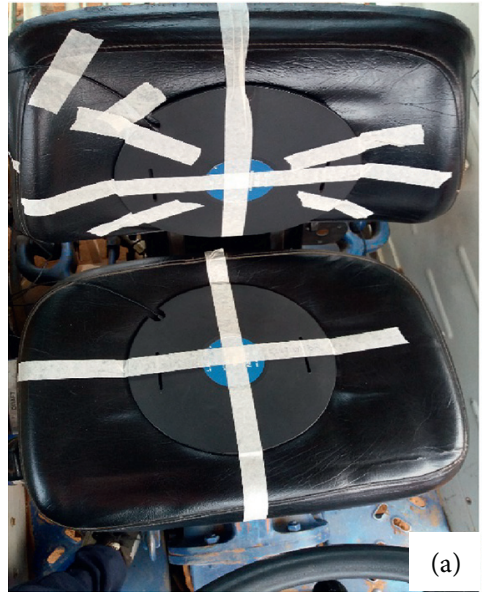

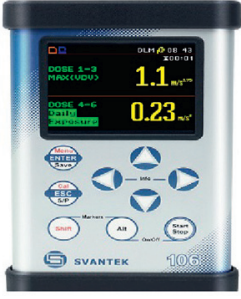

(b)

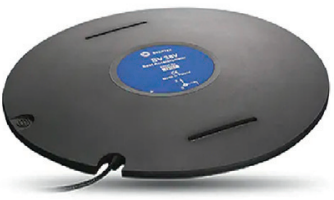

(c)

FIgURE 2: (a) Representation of experimental setup; (b) SV 106 six-channel human vibration meter and analyzer; (c) SV 38V- seat pad accelerometer.

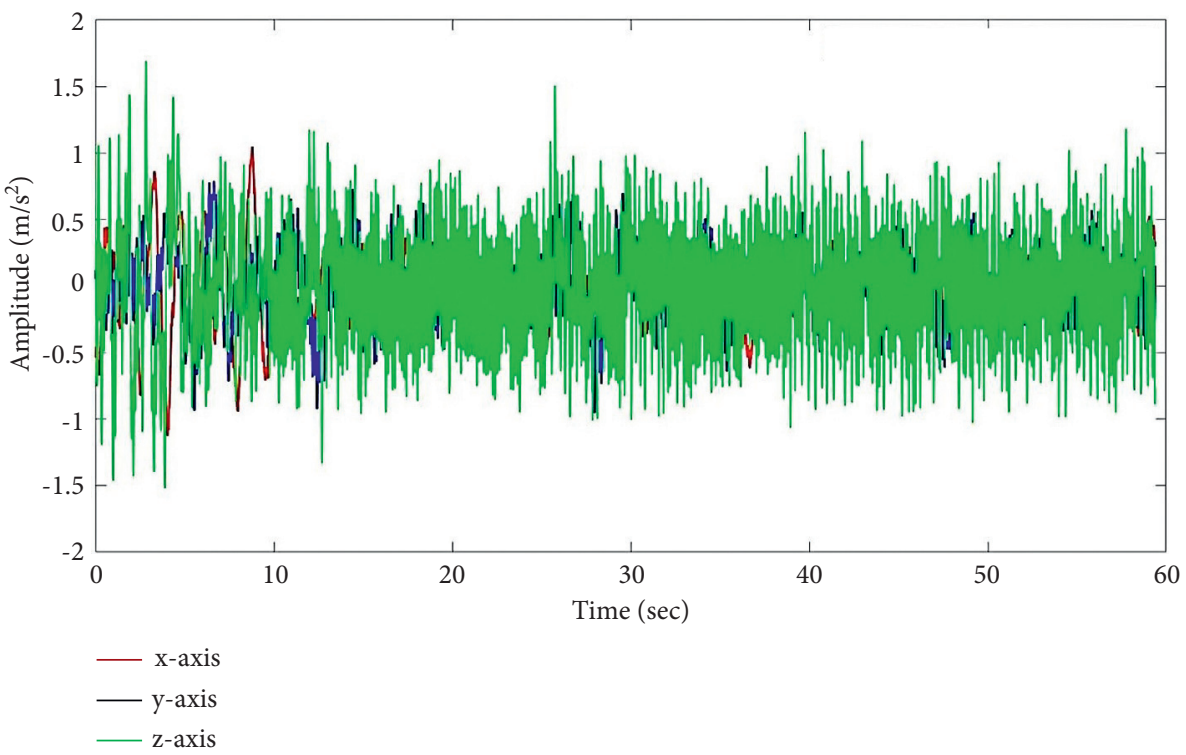

(a)

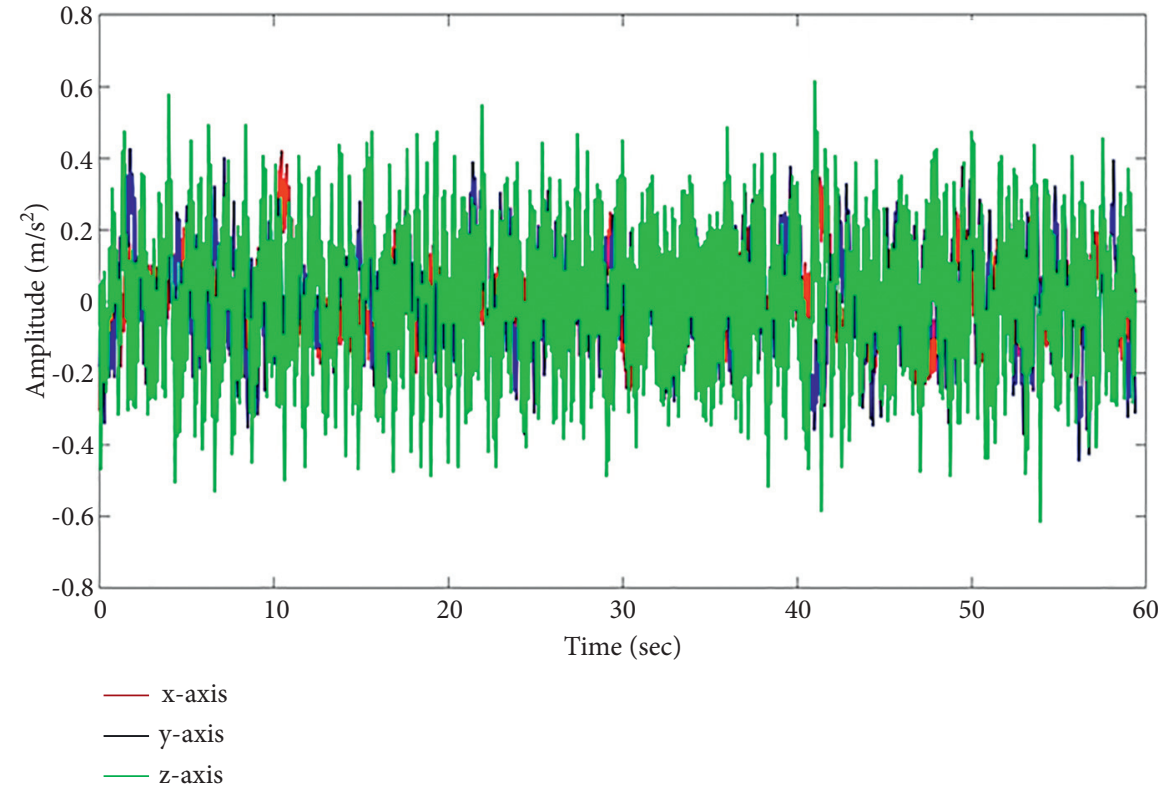

(b)

Figure 3: Mean time and amplitude response along the translational axes at (a) seat pan and (b) seat backrest. 
TABLE 1: S/N ratio of daily equivalent static compression dose $\left(\mathrm{s}_{\mathrm{ed}}(8)\right)$.

\begin{tabular}{|c|c|c|c|c|c|c|c|c|}
\hline \multirow[t]{2}{*}{ Expt. run } & \multirow[t]{2}{*}{ Tractor velocity $(\mathrm{m} / \mathrm{s})$} & \multirow[t]{2}{*}{ Tilling depth (m) } & \multirow[t]{2}{*}{ Pulling force $(\mathrm{kN})$} & \multicolumn{4}{|c|}{$\begin{array}{c}\text { Daily equivalent static } \\
\text { compression dose }\left(\mathrm{S}_{\mathrm{ed}}(8)\right)\end{array}$} & \multirow[t]{2}{*}{$\mathrm{S} / \mathrm{N}$ ratio $\left(\mathrm{S}_{\mathrm{ed}}\right)$} \\
\hline & & & & $R_{1}$ & $R_{2}$ & $R_{3}$ & $\mathrm{~S}_{\mathrm{ed}}($ Mean $)$ & \\
\hline 1 & 0.6 & 0.10 & 2 & 0.41 & 0.37 & 0.35 & 0.38 & 8.49 \\
\hline 2 & 0.6 & 0.12 & 4 & 0.45 & 0.48 & 0.46 & 0.46 & 6.68 \\
\hline 3 & 0.6 & 0.14 & 6 & 0.52 & 0.51 & 0.54 & 0.52 & 5.62 \\
\hline 4 & 0.7 & 0.12 & 2 & 0.51 & 0.56 & 0.53 & 0.53 & 5.46 \\
\hline 5 & 0.7 & 0.14 & 4 & 0.54 & 0.56 & 0.51 & 0.54 & 5.41 \\
\hline 6 & 0.7 & 0.10 & 6 & 0.55 & 0.53 & 0.58 & 0.55 & 5.14 \\
\hline 7 & 0.8 & 0.14 & 2 & 0.56 & 0.57 & 0.59 & 0.57 & 4.83 \\
\hline 8 & 0.8 & 0.10 & 4 & 0.59 & 0.59 & 0.62 & 0.60 & 4.44 \\
\hline 9 & 0.8 & 0.12 & 6 & 0.78 & 0.74 & 0.76 & 0.76 & 2.38 \\
\hline
\end{tabular}

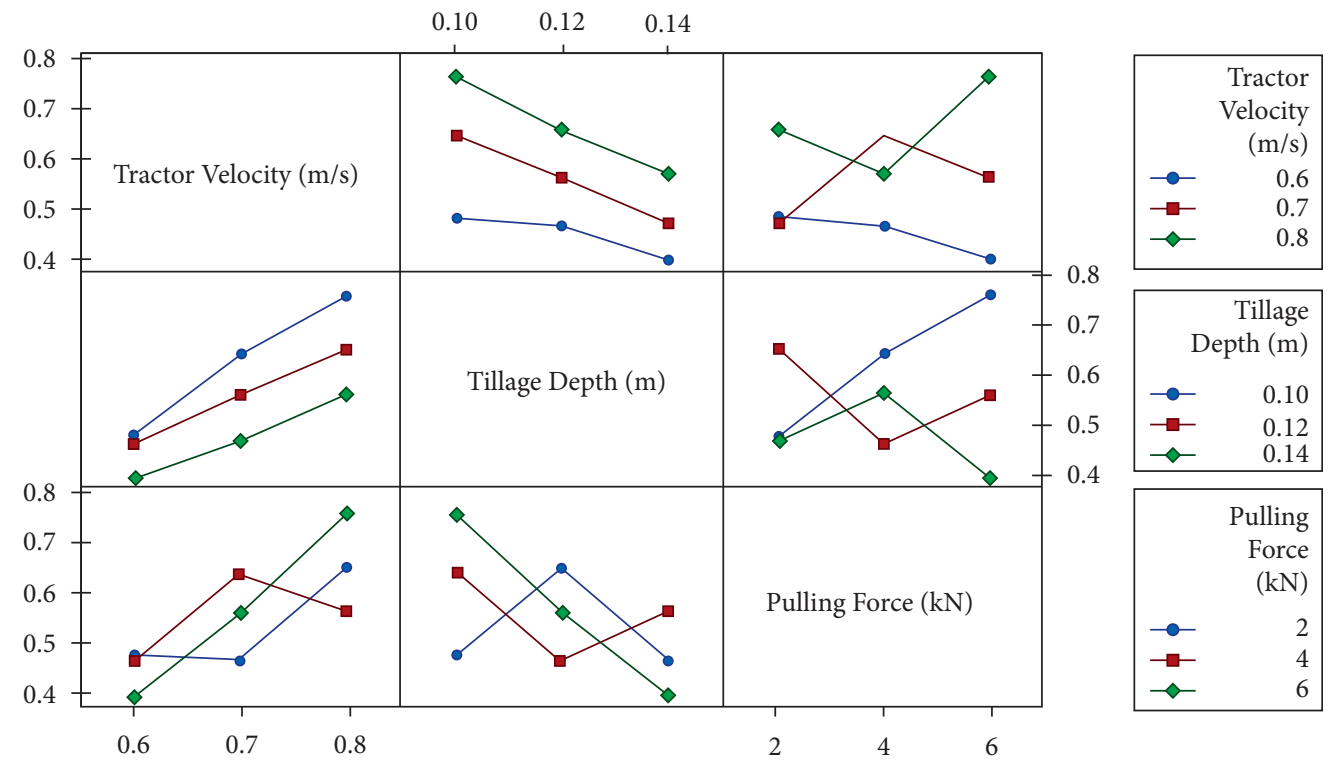

FIGURE 4: Interaction response of input parameters impacting $S_{\text {ed }}(8)$.

$0.8 \mathrm{~m} / \mathrm{s}$. It can result in an increase in acceleration peaks due to increasing vibration magnitudes $[1,25]$. These exposure levels should be controlled as they may affect the driver's health and could lead to lower physical work efficiency [24]. $\mathrm{S}_{\text {ed }}(8)$ was found to increase at a certain tilling depth up to $0.12 \mathrm{~m}$ and then subsequently decrease with the increase in depth till $0.14 \mathrm{~m}$. The interaction between tillage blades and the soil particles may hold up the vibration transmission due to the increase in friction and cohesion [26]. Furthermore, as the tilling depth increases, the vibration propagates deeper into the soil, perhaps slowing its flow into the driver's body due to the increased distance between the vibration source and the exposed body.

3.3. Analysis of Variance. The analysis of variance (ANOVA) was carried out to determine the effect of tractor velocity, tillage depth, and pulling force on $S_{\text {ed }}(8)$. The adjusted sum of squares (Adj. SS), adjusted mean of squares (Adj. MS), Ftest, and $P$ values have been computed and mentioned in Table 2. F-value determines the significant influence of the input factors on the $S_{\text {ed }}(8)$ response. The tabulated $F$-value is at a 5\% level for denominator and numerator, i.e., $F_{0.05}(2,8)=4.46$, where 2 and 8 correspond to the degree of freedom (DOF), respectively. $F$-values greater than $5 \%$ represent the significant effect of the input factor on the output factor. Furthermore, each parameter's contribution percentage $S_{\text {ed }}$ was computed by [4]

$$
P \%=\frac{\operatorname{Seq~SS}_{I}}{\mathrm{Seq} \mathrm{SS}_{T}} \times 100
$$

where Seq $\mathrm{SS}_{I}$ is the individual sequential sum of squares and Seq $\mathrm{SS}_{T}$ is the total sequential sum of squares.

Table 2 shows that tractor velocity and the pulling force had significant effect on the $S_{\text {ed }}(8)$ response, i.e., $P \leq 0.05$. Whereas, tillage depth was found to have no significant impact on $S_{\text {ed }}$ (8). In addition, the percent contribution of tractor velocity, tillage depth, and pulling was computed as $64.43 \%, 9.83 \%$, and $25.73 \%$, respectively.

3.4. Fast Fourier Transform. The raw acceleration data captured along the three-translational axes at the seat pan were used to compute the FFT response for each experiment, 
TABLE 2: Analysis of variance for $S_{\text {ed }}$ (8).

\begin{tabular}{lcccccc}
\hline Source & DF & SeqSS & AdjMS & $F$-value & $P$ value & Percentage contribution (P) \\
\hline Forward speed & 2 & 13.92 & 6.96 & 62.89 & $0.01^{*}$ & 64.43 \\
Tilling depth & 2 & 2.12 & 1.06 & 9.58 & 0.09 & 9.83 \\
Pulling force & 2 & 5.34 & 2.67 & 24.14 & $0.04^{*}$ & 24.73 \\
Residual error & 2 & 0.22 & 0.11 & & & 1.01 \\
Total & 8 & 21.60 & & & 100.00 \\
\hline
\end{tabular}

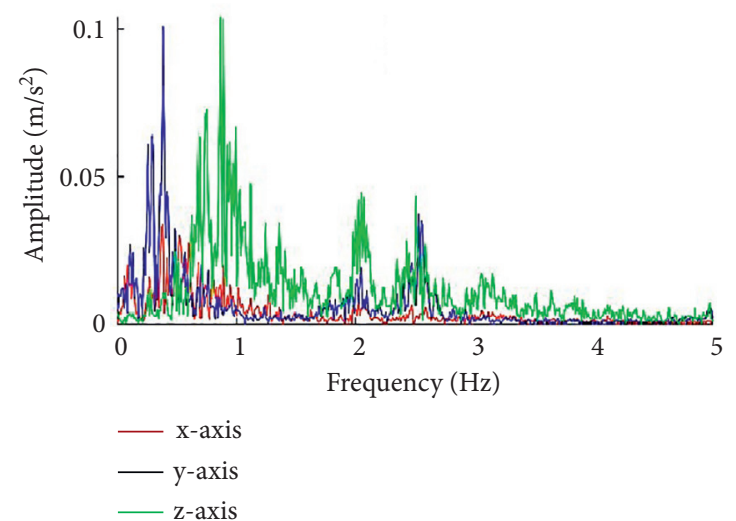

(a)

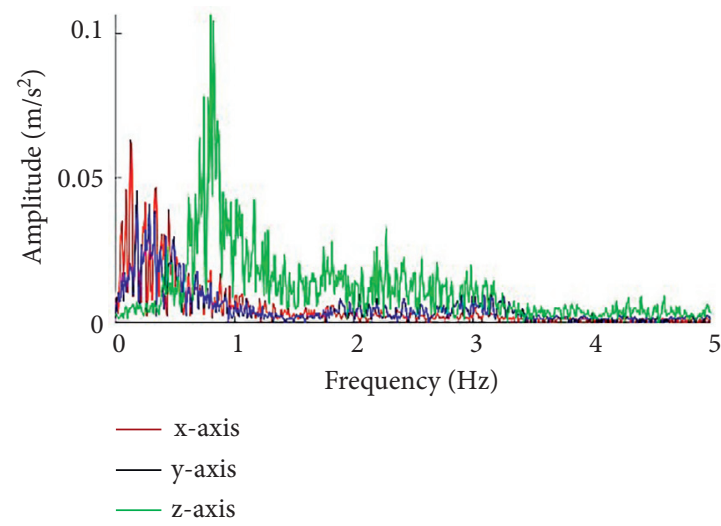

(c)

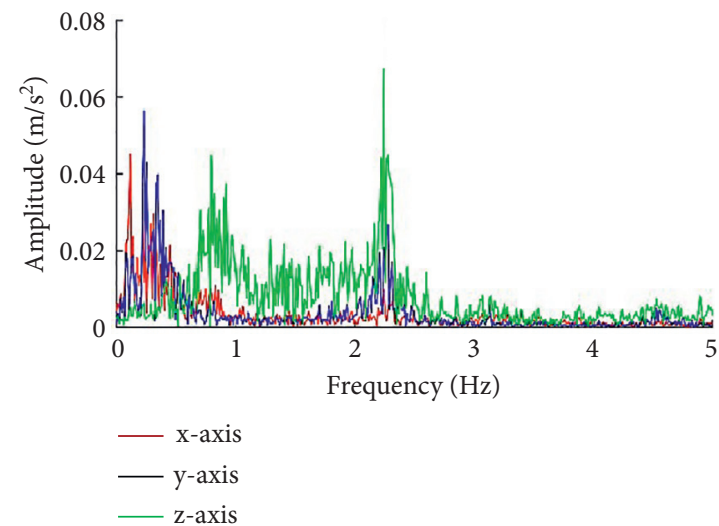

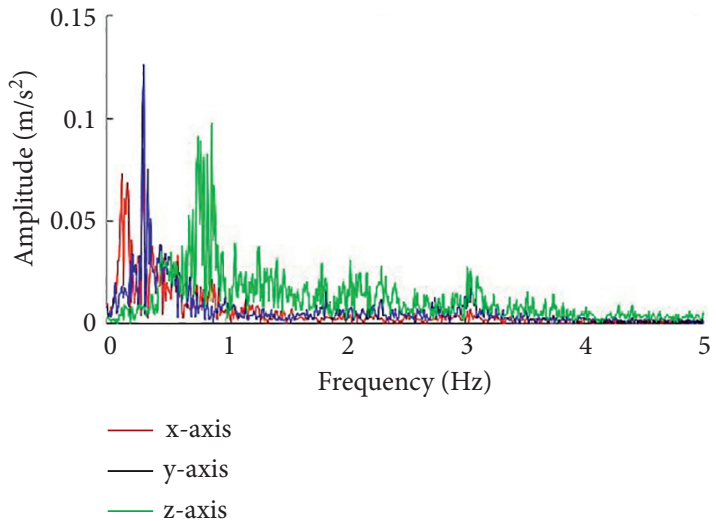

(b)

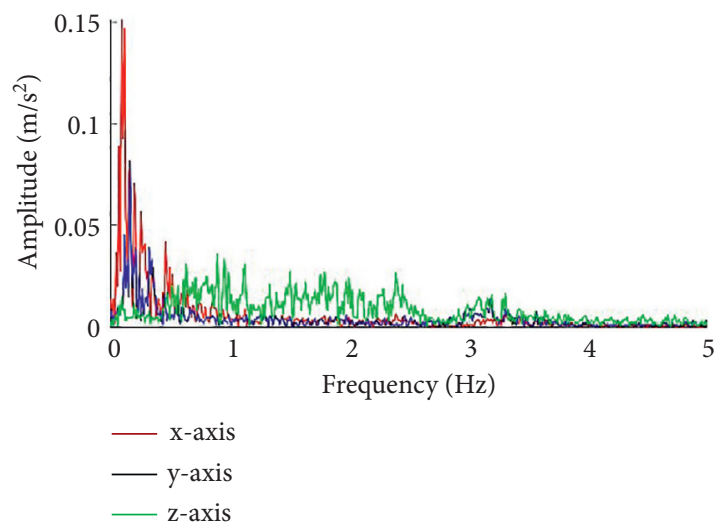

(d)

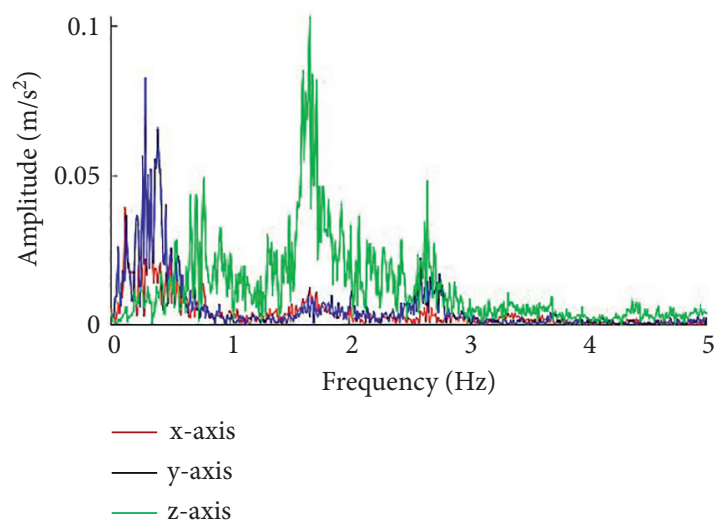

(f)

Figure 5: Continued. 


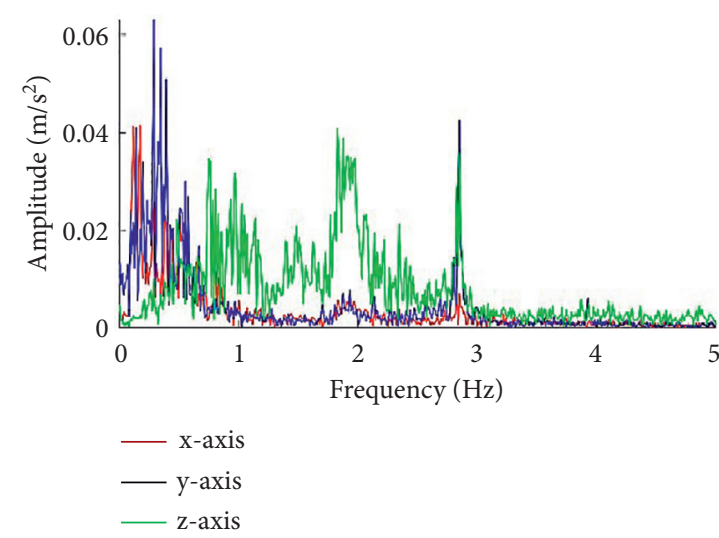

(g)

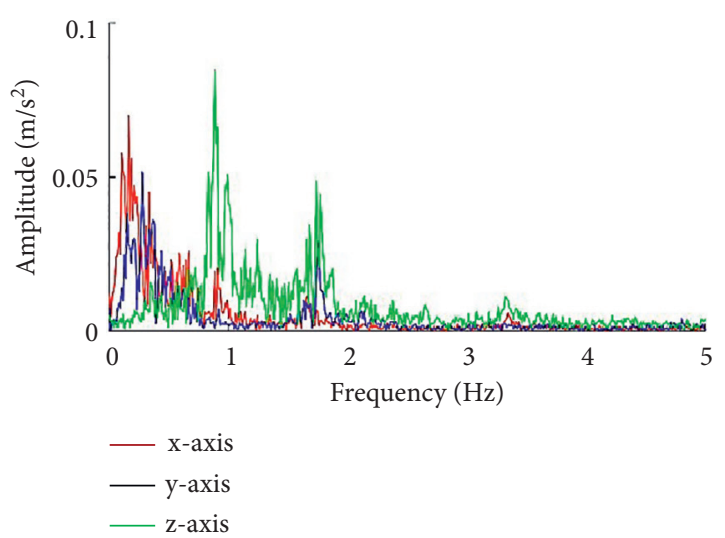

(h)

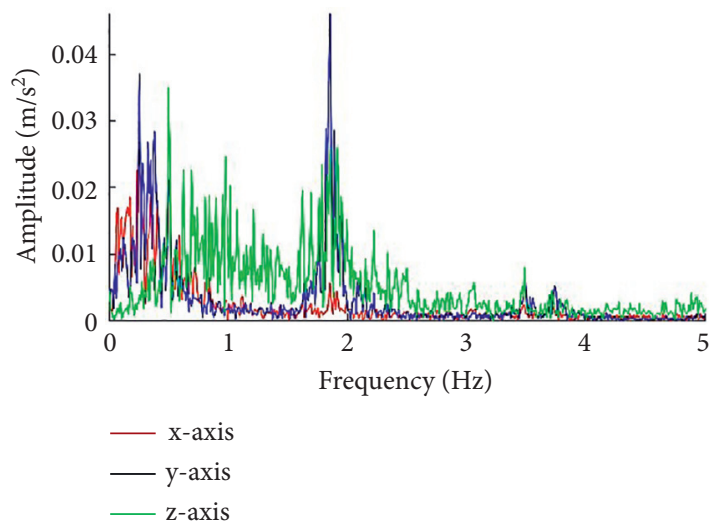

(i)

FIGURE 5: Fast Fourier transform response of the acceleration measured at seat pan during the experiments (a-i).

as shown in Figure 4. FFT response showed the dominant frequencies during the rotavator tillage operation. The majority of past research studies had computed FFTs in the controlled lab environment using the driving simulators. In this system, the input vibration had the same energy over the entire frequency range. However, the vibration energy never remains constant with respect to the whole frequency range in the real field testing. So, it has been decided to present data in terms of r.m.s. acceleration responses and the FFT of the raw acceleration data at the seat pan [27]. It can be visualized that the FFT response indicated the entire dominant frequencies under the low-frequency range. Most of the experiments showed primary dominant frequency peaks along the vertical axis. However, experiments $g$ and $i$ showed the dominant frequency along the lateral axis, as shown in Figures 5(g) and 5(i). These low frequencies are the result of the human body's natural frequencies and indeed cause discomfort and other musculoskeletal problems particularly in the lumbar region $[13,18,28]$.

\section{Conclusions}

TThe mean vibration response was found dominant along the vertical $(z)$ axis. In addition, the majority of vibration exposures were beyond the exposure action value, i.e.,
$0.5 \mathrm{~m} / \mathrm{s}^{2}$ as recommended by Directive 2002/44/EU [6]. Tractor velocity and pulling force were found to have a significant impact on $\mathrm{S}_{\mathrm{ed}}(8)$ with a percentage contribution of $64.43 \%$ and $27.73 \%$. Fast Fourier transform provided various dominant frequencies that facilitate understanding of the impact of ride parameters on the $S_{\text {ed }}$ (8) response under actual field conditions. Moreover, the dominant frequencies of vibration were found in the lower range which could affect human health due to coincidence with natural frequencies of human body parts and resultant resonance. The present study has been carried out using one tractor driver, whereas future investigation may include drivers with different age and BMI groups. The number of experiments can be increased or the design of experiments may vary to get more generalized results.

\section{Data Availability}

The entire experimentation data used to support the findings of this study are included within the article.

\section{Conflicts of Interest}

The authors declare that they have no conflicts of interest. 


\section{Acknowledgments}

The authors are grateful for financial assistance for the present work to All India Council of Technical Education under Grant "MODROBs" [9-23/RIFD/MODROB/Policy1/2017-19] and "RPS" [8-48/FDC/RPS (Policy-1)/2019-20]. The authors are grateful for the experimental facility provided by the Department of Farm Machinery and Energy Engineering, Punjab University, Ludhiana, Punjab, India. The authors would also like to thank the subject for their contribution during the entire experimentation.

\section{References}

[1] C. R. Mehta, P. S. Tiwari, and A. C. Varshney, "Ride vibrations on a $7 \cdot 5 \mathrm{~kW}$ rotary power tiller," Journal of Agricultural Engineering Research, vol. 66, no. 3, pp. 169-176, 1997.

[2] A. Singh, L. P. Singh, S. Singh, H. Singh, and C. Prakash, "Investigation of occupational whole-body vibration exposure among Indian tractor drivers," International Journal of $\mathrm{Hu}$ man Factors and Ergonomics, vol. 5, no. 2, pp. 151-165, 2018.

[3] A. Prakash, G. S. Manes, A. Dixit, and M. Singh, "Performance status of rotavators being manufactured in Punjab," Journal of The Institution of Engineers (India): Series A, vol. 94, no. 1, pp. 53-58, 2013.

[4] A. Singh, L. P. Singh, S. Singh, H. Singh, N. K. Chhuneja, and M. Singh, "Evaluation and analysis of occupational ride comfort in rotary soil tillage operation," Measurement, vol. 131, pp. 19-27, 2019.

[5] M. J. Griffin, "Discomfort from feeling vehicle vibration," Vehicle System Dynamics, vol. 45, no. 7-8, pp. 679-698, 2007.

[6] E. U. Directive and G. E. Provisions, "Directive 2002/44/EC of the European Parliament and the Council of 25 June 2002 on the minimum health and safety requirements regarding the exposure of workers to the risks arising from physical agents (vibration) (sixteenth individual Directive within the meaning of Article 16 (1) of Directive 89/391/EEC)," Official Journal of the European Communities-Legislation, vol. 117, no. 13, pp. 6-7, 2002.

[7] R. Hildebrand, E. Keskinen, and J. A. R. Navarrete, "Vehicle vibrating on a soft compacting soil half-space: ground vibrations, terrain damage, and vehicle vibrations," Journal of Terramechanics, vol. 45, no. 4, pp. 121-136, 2008.

[8] L. Solecki, "Assessment of annual exposure of private farmers to whole body mechanical vibration on selected family farms of plant production profile," Annals of Agricultural and Environmental Medicine, vol. 17, no. 2, pp. 243-250, 2010.

[9] C.-C. Liang and C.-F. Chiang, "Modeling of a seated human body exposed to vertical vibrations in various automotive postures," Industrial Health, vol. 46, no. 2, pp. 125-137, 2008.

[10] S. P. Harsha, M. Desta, A. S. Prashanth, and V. H. Saran, "Measurement and bio-dynamic model development of seated human subjects exposed to low frequency vibration environment," International Journal of Vehicle Noise and Vibration, vol. 10, no. 1-2, pp. 1-24, 2014.

[11] A. Kumar, P. Mahajan, D. Mohan, and M. Varghese, "ITinformation technology and the human interface," Journal of Agricultural Engineering Research, vol. 80, no. 4, pp. 313-328, 2001.

[12] I. J. H. Tiemessen, C. T. J. Hulshof, and M. H. W. FringsDresen, "Low back pain in drivers exposed to whole body vibration: analysis of a dose-response pattern," Occupational and Environmental Medicine, vol. 65, no. 10, pp. 667-675, 2008.

[13] M. J. Griffin, Handbook of Human Vibration, Academic Press, London, 2012.

[14] C. R. Mehta and V. K. Tewari, "Damping characteristics of seat cushion materials for tractor ride comfort," Journal of Terramechanics, vol. 47, no. 6, pp. 401-406, 2010.

[15] T. J. Lehtonen and M. Juhala, "Predicting the ride behaviour of a suspended agricultural tractor," International Journal of Vehicle Systems Modelling and Testing, vol. 1, no. 1/2/3, pp. 131-142, 2005.

[16] V. N. Nguyen and S. Inaba, "Effects of tire inflation pressure and tractor velocity on dynamic wheel load and rear axle vibrations," Journal of Terramechanics, vol. 48, no. 1, pp. 3-16, 2011.

[17] H. Ciloglu, M. Alziadeh, A. Mohany, and H. Kishawy, "Assessment of the whole body vibration exposure and the dynamic seat comfort in passenger aircraft," International Journal of Industrial Ergonomics, vol. 45, pp. 116-123, 2015.

[18] S. Rakheja, R. G. Dong, S. Patra, P.-É. Boileau, P. Marcotte, and C. Warren, "Biodynamics of the human body under whole-body vibration: synthesis of the reported data," International Journal of Industrial Ergonomics, vol. 40, no. 6, pp. 710-732, 2010.

[19] E. Sorainen, J. Penttinen, M. Kallio, E. Rytkönen, and K. Taattola, "Whole-body vibration of tractor drivers during harrowing," American Industrial Hygiene Association Journal, vol. 59, no. 9, pp. 642-644, 1998.

[20] M. Muzammil, S. S. Siddiqui, and F. Hasan, "Physiological effect of vibrations on tractor drivers under variable ploughing conditions," Journal of Occupational Health, vol. 46, no. 5, pp. 403-409, 2004.

[21] International Organization of Standardization (2631-5), Mechanical Vibration and Shock - Evaluation of Human Exposure to Whole-Body Vibration - Part 5: Method for Evaluation of Vibration Containing Multiple Shocks, International Organization of Standardization, Geneva, Switzerland, 2004.

[22] S. K. Karna and R. Sahai, "An overview on Taguchi method," International journal of engineering and mathematical sciences, vol. 1, no. 1, pp. 1-7, 2012.

[23] International Organization for Standardization Iso 2631-1 (E), Mechanical, International Organization of Standardization, Geneva, Switzerland, 1997.

[24] B. Sam and K. Kathirvel, "Vibration characteristics of walking and riding type power tillers," Biosystems Engineering, vol. 95, no. 4 , pp. 517-528, 2006

[25] P. Taylor, J. Village, and C. Trask, "Assessing whole body vibration exposure for use in epidemiological studies of back injuries:measurements, observations and self-reports," Ergonomics, vol. 55, no. 4, pp. 37-41, 2012.

[26] D.-S. Kim and J.-S. Lee, "Propagation and attenuation characteristics of various ground vibrations," Soil Dynamics and Earthquake Engineering, vol. 19, no. 2, pp. 115-126, 2000.

[27] M. G. R. Toward and M. J. Griffin, "The transmission of vertical vibration through seats: influence of the characteristics of the human body," Journal of Sound and Vibration, vol. 330, no. 26, pp. 6526-6543, 2011.

[28] A. Sharma and B. B. Mandal, "Attenuation of mechanical vibration during transmission to human body through mining vehicle seats," Mining, Metallurgy \& Exploration, vol. 38, no. 3, pp. 1449-1461, 2021. 